\title{
Experimental and Finite Element Analysis of the Open-Cells Porous Materials Subjected to Compression Mechanical Loading
}

\author{
LUCIA-ANTONETA CHICOS ${ }^{1}$, IAN CAMPBELL², SEBASTIAN MARIAN ZAHARIA ${ }^{1}$, MIHAI ALIN POP3*, CAMIL LANCEA ${ }^{1}$, \\ AUGUSTIN SEMENESCU 4 , BOGDAN FLOREA4, OANA ROXANA CHIVU 5 \\ ${ }^{1}$ Transilvania University of Brasov, Faculty of Technological Engineering and Industrial Management, Department of Manufacturing \\ Engineering, 5 Mihai Viteazu Str., 500174, Brasov, Romania \\ ${ }^{2}$ Loughborough University, Design School, Epinal Way, Loughborough, Leicestershire, LE11 3TU, United Kingdom \\ ${ }^{3}$ Transilvania University of Brasov, Faculty of Materials Science and Engineering, Department of Materials Science, 1 Colina \\ Universitatii Str., 500084, Brasov, Romania \\ ${ }^{4}$ University Politehnica of Bucharest, Faculty of Material Science and Engineering, 313 Splaiul Independentei, 060021, Bucharest, \\ Romania \\ ${ }^{5}$ University Politehnica of Bucharest, Faculty of Engineering and Management of Technological Systems, 313 Splaiul Independentei, \\ 060021, Bucharest, Romania
}

\begin{abstract}
Progress in Additive Manufacturing (AM) technology enables the fabrication of complex structures that could not be obtained with traditional manufacturing methods. One AM research area is the development and use of lightweight products with cellular structures, containing complex lattices and pores, which give improved performance and functionality. It is well known that there is a strong link between mechanical properties and architecture of samples with cellular structures. This paper presents a comparison and validation of Finite Element Analysis (FEA) simulations of cellular structures with experimental data obtained from compression tests, and degradation behaviour under load compression. The specimens, with spherical open-cells, were produced in VeroClear RGD810 photopolymer resin. Mechanical compression tests were performed to investigate the compressive behaviour and the mechanical response was registered in the form of compressive stress-strain curves. Also, using the specimens' CAD data and compression test parameters, a Finite Element Analysis (FEA) was performed. A macroscopic analysis of the specimens' structure and microhardness tests before and after compression tests were also carried out.
\end{abstract}

Keywords: additive manufacturing, compression tests, Final Element Analysis, cellular solids, spherical cells, open-cells

Gibson and Ashby [1-3] defined a cellular solid as one made up of an interconnected network of solid struts or plates which form edges and faces of cells [4]. There are two types of cellular solids: (a) 2D cellular solids such as honeycombs, with a geometry that is defined in 2D, (b) 3D cellular solids (foams) which are generally highly porous $3 \mathrm{D}$ structures that are divided into distinct cells. A cell is an empty space delimited by solid boundaries. The second category can be further divided into two subgroups. If the material is distributed in the faces and struts of the cells, the cellular solid is often called a closed-cell foam. If the material is in the struts only (so that the cells are connected through open faces), the cellular solid is called an opencell foam $[1,2,4,5]$.

Cellular solids are a very important class of materials with diverse applications ranging from thermal insulation and shock absorbing, to light-weight structural components. They constitute crucial components in a large number of industries including automotive, aerospace, marine, biomedical, and packaging. In many of these applications the foam material is subjected to long periods of continuous stress, which can, over time, lead to a permanent change in structure and a degradation in performance [6].

There are several conventional manufacturing methods used for the fabrication of cellular materials, such as mixing metal pow ders with a blowing agent, bubbling gas through a liquid, and injecting gas directly into a molten solid [5, 3], which result in cellular structures consisting of randomly oriented and shaped structural units. Although these methods allow certain parameters of the cellular structures, including the relative density, cell size and shape, to be controlled, they still exhibit some limitations around control of pore size or morphology [7].

To overcome these drawbacks, Additive Manufacturing (AM) has been proposed in recent decades as an alternative means of making cellular materials. With the advent of this technology, it is now possible to create uniform structures with well-defined cellular shapes and dimensions using different types of materials (polymers, ceramics, and metals). AM can be defined as a layer by layer building of 3D structures defined in a Computer Aided Design (CAD) model. It enables the fabrication of new porous structures with complex shapes and tailored mechanical properties. In most cases, these techniques are used to fabricate both periodic structures and random foams $[6,7]$. Periodic structures use templates characterized by a unit cell that can be translated through the structure in two or three dimensions. Different AM techniques have been used for manufacturing cellular solids including Stereolithography (SL), Fused Deposition Modeling (FDM), Polyl et, Electron Beam Melting (EBM), Laser Sintering (LS), Selective Laser Melting (SLM), and Wire Arc Additive Manufacturing (WAAM) $[4,7]$.

Although there is a large amount of research conducted on the generation of cellular structures, there is little work regarding the simulation of such structures using Finite Element Analysis (FEA).

A significant amount of variance between empirical results and simulation data has been found repeatedly within a variety of studies. Ajoku, et al [8] show that there is a significant error between the experimental and theoretical elastic modulus of Nylon-12. Shen, et al [9]

\footnotetext{
* email: mihai.pop@unitbv.ro
} 
demonstrate that there is a significant error between a numerical analysis simulation and traditional FEA modelling in SLS due to the inability to describe the porosity of the sintered material in traditional FEA products. In Kadkhodapour, et al [10] deformation procedure and stress-strain curves were simulated by FEA and exhibited good agreement with the experimental observation. In Michailidis, et al [11] both experimental results and FEA simulations revealed that the distributions of local stresses and strains depend on size, orientation, and spatial arrangement of the pores. Also, quantitative comparison of the stress-strain curves derived from experimental and computational results showed good agreement. Mark, et al [12] showed through a variety of further testing that the solutions of the simulated tests being non-convergent to the empirical data was caused by the non-uniform distribution of porosity within the specimen.

The aim of this study was to explore the behaviour of FEA simulations conducted on cellular structure specimens through inverse testing, using data recorded from experimental compression tests. A comparison between simulated and empirical compression tests was undertaken in order to compare the degradation behaviour between the specimens made of acrylate polymer using Polyl et technology, and FEA. To establish the degradation on a structural level optical, macrostructural analysis was carried out.

\section{Experimental part Materials}

The CAD model of a cylindrical foam specimen with $12.7 \mathrm{~mm}$ diameter and $25.4 \mathrm{~mm}$ height is shown in figure 1. To distribute the load more evenly, the specimens had 2 $\mathrm{mm}$ cap layers on the top and bottom surfaces.

The cellular solids with spherical open-cells had $55 \%$ porosity and the diameter of the spheres was $3.8 \mathrm{~mm}$. The polymeric foams considered in this work (fig. 2) were made from the VeroClear RGD810 photopolymer and fabricated using a Connex 500 printer, which utilizes the Polyl et 3D printing technique. For compression testing, five specimens with identical arhitecture were manufactured and one of them is shown in figure 2 .

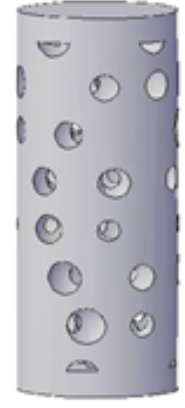

Fig. 1. Specimen CAD model

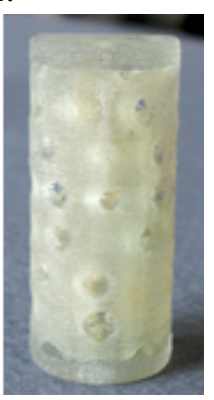

Fig. 2. Specimen before compression test
Polyl et 3D printing is a material jetting process, wherein droplets of liquid photopolymer are deposited directly onto a build tray and then cured with a UV light [13, 14]. The
Polyj et process offers a high resolution print, with a layer thickness down to 16 microns. VeroClear RGD810 is a rigid, transparent Polyj et material featuring great dimensional stability [14]. The characteristics of VeroClear RGD810 photopolymer are presented in table 1.

\section{Testing procedure}

Uniaxial compression tests were performed on the foam test specimens according to the ASTM D-695 (ISO 604) Standard Test Method for Compressive Properties of Rigid Plastics, test method. This covers the determination of the mechanical properties of unreinforced and reinforced rigid plastics, including high modulus composites or cellular structures, when loaded in compression at relatively low uniform rates of straining or loading.

Compression tests were performed on the five specimens at room temperature using an INSTRON 3366 Dual Column Testing System. Its maximum axial load capacity is $10 \mathrm{kN}$. Data was collected automatically by the Instron Bluehill 3 program. All specimens were slightly pre-stressed in order to eliminate any planarity errors. Thereafter, a constant compression displacement rate was applied to the specimen, equal to $6 \mathrm{~mm} / \mathrm{min}$. Tests were controlled by extension and the load measured since the compressive strength of the specimens was unknown.

For the analysis of compression behaviour of the specimens in the numerical/simulated environment, the Ansys 15 software system was used. The CAD model of the specimens and the data obtained from the experimental compression tests constituted the input data for the Ansys 15 system. FEA analysis was performed to compare the compression behaviour of specimens in real and numeric/simulated environment.

The analysis of the cellular structure deformation and, in particular, the breaking of the cell walls, deformation of cells and propagation of cracks under the action of compressive forces was performed by optical analyzing of the microstructure using Omnimet-Buehler Microscope system provided with a Nikon microscope (with a resolution up to $1000 \mathrm{x}$ ).

The microhardness of the specimen material, before and after compression tests, was measured on the Microhardness Test FM 700. For this purpose the following parameters were used: $10 \mathrm{gf}$ load and a time of $10 \mathrm{~s}$.

\section{Results and discussions}

\section{Compression experimental tests of the specimens}

As mentioned before, uniaxial compression experiments were carried out on the foam test specimens using the ASTM D 695 standard. One of the foam specimens immediately after the compression test is shown in figure 3. To examine the material specimen response to physical testing, each specimen was compressed with loads which were applied through the top face. As the force was increased, the equipment recorded the strain induced in the specimen.

Mechanical properties of cellular solids depend strongly on the properties of the constituent material, the relative

\begin{tabular}{|l|l|l|l|}
\hline VeroClear RGD810 & ASTM & UNITS & METRIC \\
\hline Tensile strength & D-638-03 & MPa & $50-65$ \\
\hline Modulus of elasticity & D-638-04 & $\mathrm{MPa}$ & $2000-3000$ \\
\hline Flexural Strength & $\mathrm{D}-790-03$ & $\mathrm{MPa}$ & $75-110$ \\
\hline Flexural Modulus & $\mathrm{D}-790-04$ & $\mathrm{MPa}$ & $2200-3200$ \\
\hline Water Absorption & D-570-98 24hr & $\%$ & $1.1-1.5$ \\
\hline Shore Hardness (D) & Scale D & Scale D & $83-86$ \\
\hline Rockwell Hardness & Scale M & Scale M & $73-76$ \\
\hline Polymerized density & ASTM D792 & $\mathrm{g} / \mathrm{cm} 3$ & $1.18-1.19$ \\
\hline
\end{tabular}

Table 1

VEROCLEAR RGD810 PHOTOPOLYMER CHARACTERISTICS [14] 
density of the foam, and the details of the microstructure. Under the action of the compressive force, all five specimens had similar behavior, being destroyed as a result of the occurrence of shear band (fig. 3, and fig. 4).

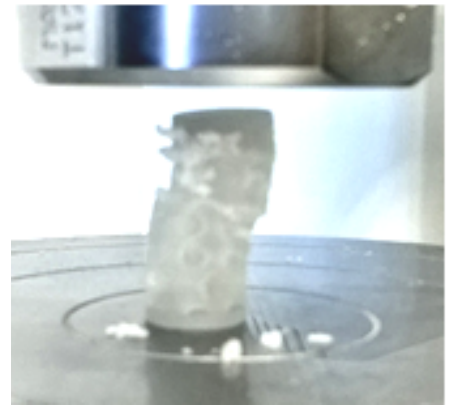

Fig. 3. Specimen immediately after compression test

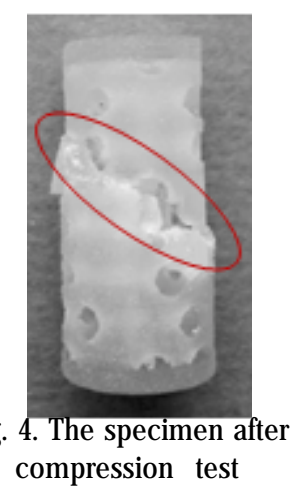

Figure 5 shows the compressive load - strain curves for the five specimens with identical arhitecture and material. The results presented show the repeatability of the data.

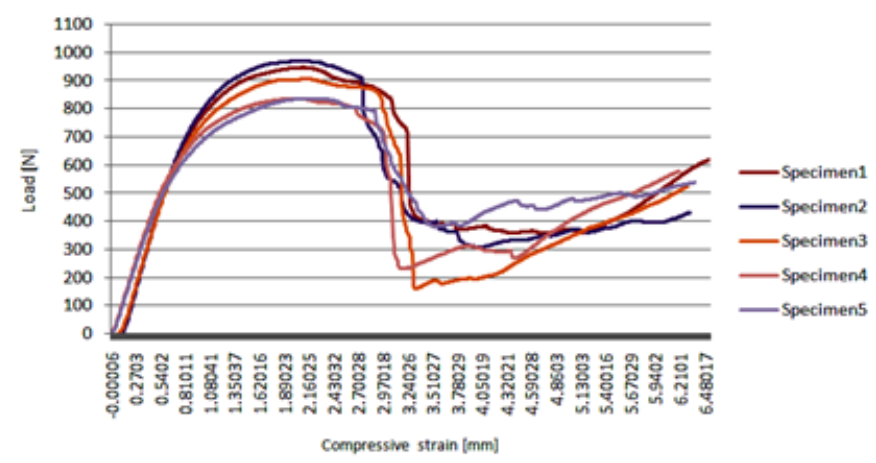

Fig. 5. Load-compressive strain curves
In figure 5, the curves start with a region of linear elastic deformation, followed by a plateau stage with a smooth increase in strain as the load increases. In this region the spherical pores are compressed, distorted, and the cell walls are subject to a shearing load. Eventually, this causes the cell walls to crack after which, a densification stage occurr with a resulting drop in load. Finally, the densified specimens once again follow an upward load - strain trajectory, but the curve is no longer smooth.

\section{FEA of the specimens subjected to compression}

The specimens were modelled in Autodesk AutoCAD 2010, converted to the SAT format, and then imported into the Ansys 15 package for finite element analysis, with approximately 52,000 elements being used. The discretization was done with tetrahedronal elements using the TET10topology. The shape of the elements seen on the surface was therefore triangular.

As for the boundary conditions, the lower cap elements were fixed for displacement and a compressive displacement of $6 \mathrm{~mm}$ (similar to that in the experimental tests) was applied to the upper cap.

Figure 6 shows the build-up of principal stresses that lead to the first cracks (fig.6. a) in the specimens and their propagation (fig.6. b).

Figure 7 shows the first appearance (fig.7. a) and propagation of the deformations both inside (fig.7. a-d) and outside of the specimen (fig.7. e).

The results of the analysis reveal that higher values of maximum stress were noticed at the edges of the interconnected windows (fig.6. c, d), where in fact the edge is very sharp, thus the angles in corners of some elements could be very small.

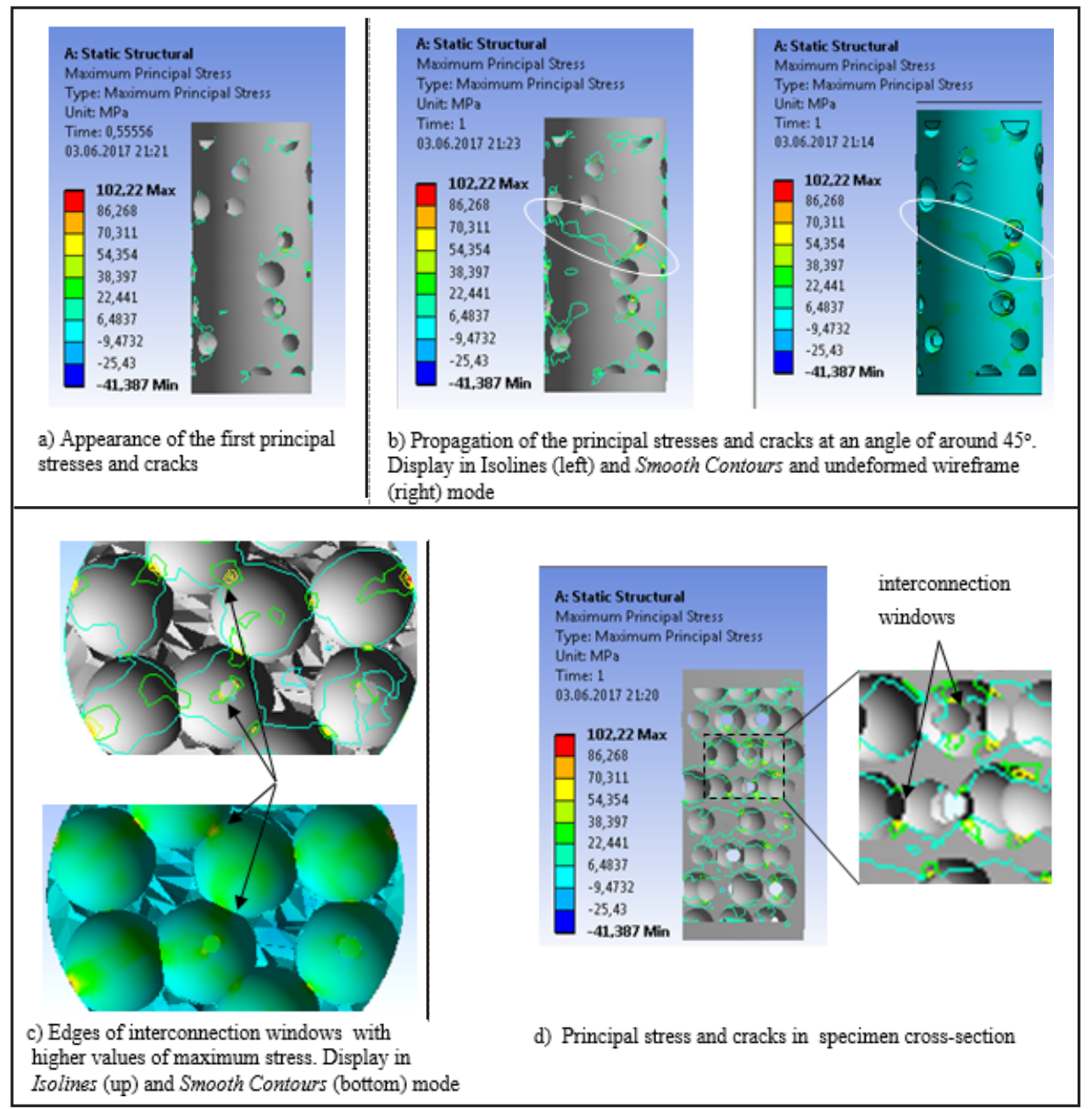

Fig. 6. Maximum principal stress in FEA 


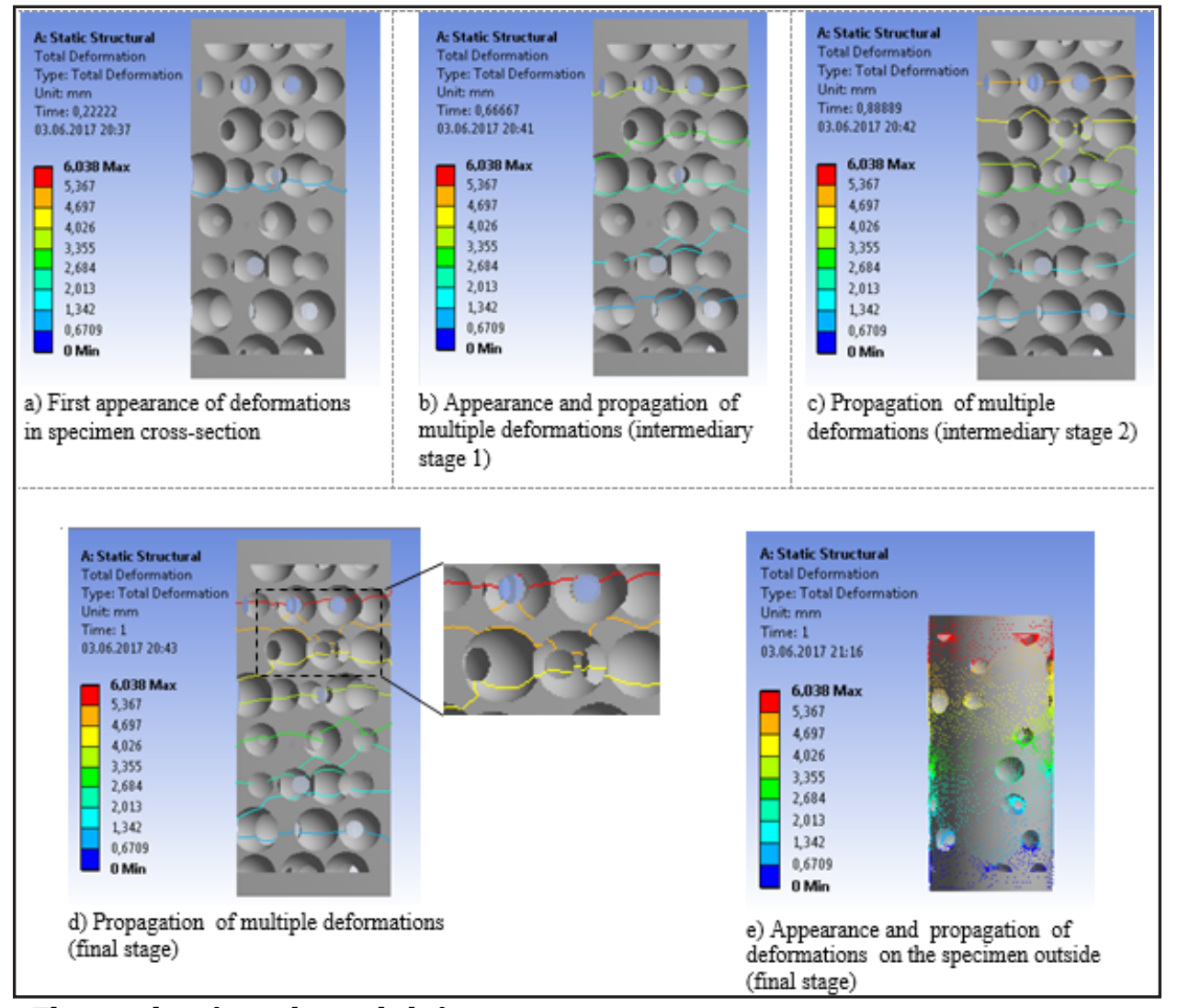

Fig.7. Appearance and propagation of deformations in FEA simulation

The mode of cracks and deformations propagation (marked area in fig.6. b) resulting from FEA are similar to experimental results. Both in FEA and experimental compression tests (fig. 4) the specimens shearing band appeared in approximately the same area.

\section{Macroscopic analysis of the specimens' structure and} microhardness tests

For the physical specimens subjected to compression loads, macroscopic (25x) and microscopic (100x) analyzes were performed. This was done in order to identify the

deformation and deterioration of the spherical pores and propagation of cracks in their walls.

It was found that in most cases where cells wall cracking occurs due to compressive forces, it occurs at an oblique angle of around $45^{\circ}$ (fig. 6. b, and fig. 8. a-c, e), which causes the shearing band to appear in the specimens fig. 4.). The breaking of the cells walls is followed by the densification of the material (fig. 8. g, h) as well as its dislocation (fig.8. d, e, i).

The microhardness of the specimens' material was

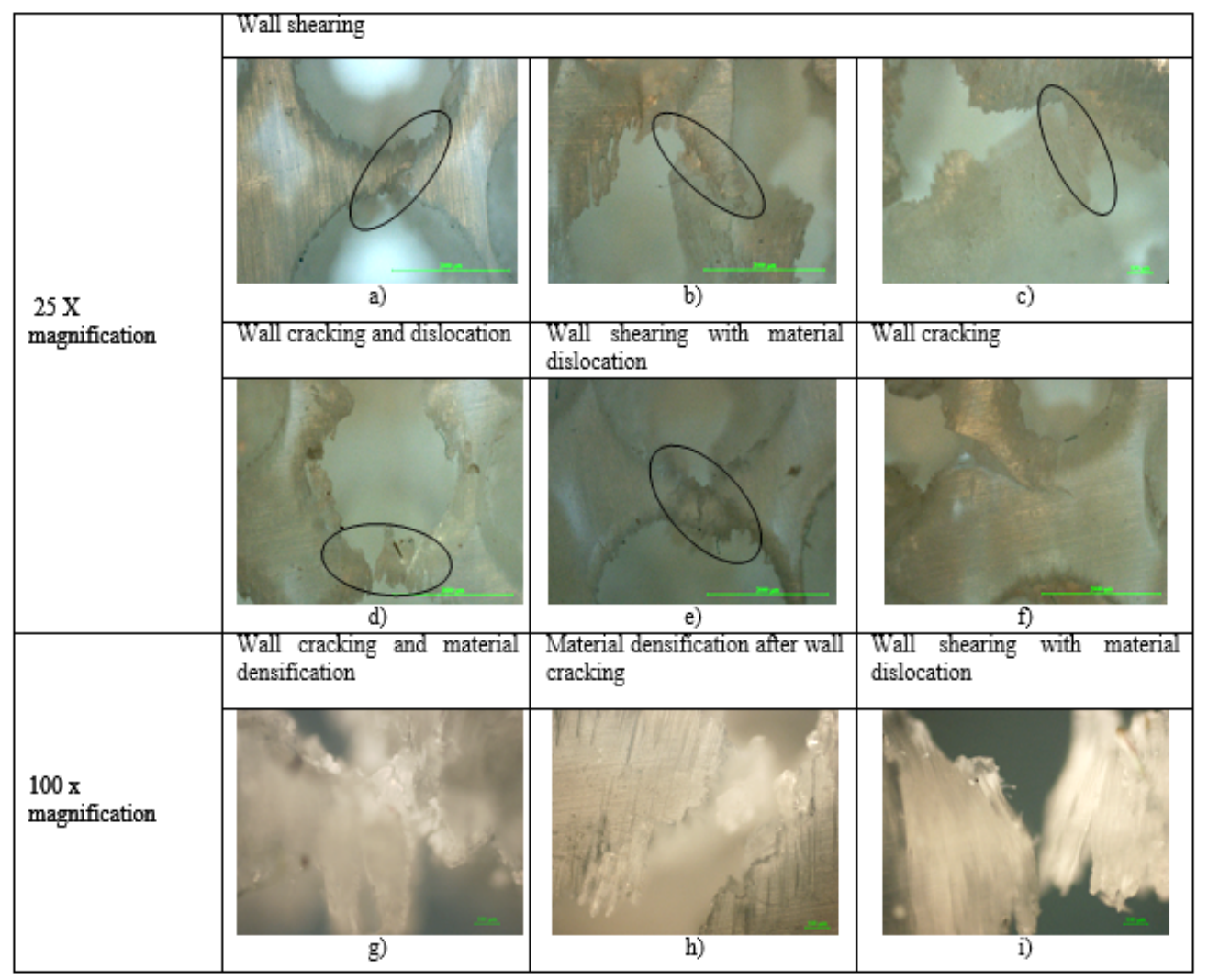

Fig. 8. Macroscopic analysis of the specimens' structure 
analyzed before and after compression. To determine the microhardness, 11 determinations were performed with a loading of $10 \mathrm{gf}$ and a time of $10 \mathrm{~s}$ being used. Table 2 presents the results of the specimens' microhardness analysis.

Tabel 2

MICROHARDNESS ANALYSIS RESULTS

\begin{tabular}{|c|c|c|}
\hline $\begin{array}{c}\text { Test } \\
\text { no. }\end{array}$ & \multicolumn{2}{|c|}{ Microhardness value (HV) } \\
\hline & $\begin{array}{c}\text { Specimen before } \\
\text { compression test }\end{array}$ & $\begin{array}{c}\text { Specimen after } \\
\text { compression test }\end{array}$ \\
\hline 1. & 16.9 & 10.8 \\
\hline 2. & 22.3 & 17.7 \\
\hline 3. & 20.6 & 16.3 \\
\hline 4. & 20.4 & 14.7 \\
\hline 5. & 24.0 & 18.1 \\
\hline 6. & 15.1 & 17.2 \\
\hline 7. & 19.3 & 16.0 \\
\hline 8. & 16.7 & 15.7 \\
\hline 9. & 20.8 & 18.4 \\
\hline 10. & 17.2 & 16.3 \\
\hline 11. & 21.6 & 19.8 \\
\hline
\end{tabular}

After removing the minimum and maximum values, an average value for microhardness of HVmed $=19.35$ was obtained for pre-test specimens and an average value of HVmed $=16.71$ for post-test specimens.

Considering the results presented in Table 2 , there is a notable decrease in the microhardness of the specimen subjected to the compression tests. It is believed that this decrease is caused by the occurrence of micro-cracks in the material under the action of the compressive load.

\section{Conclusions}

The rapid development of Additive Manufacturing technology has opened the door to manufacturing complex cellular structures that could notbe obtained with traditional manufacturing technologies. In this study the authors have presented a Finite Element Analysis (FEA) simulation of cellular structure specimens and compared the results with empirical data obtained from physical compression tests.

Finite Element Analysis was used to investigate how the deformation occurs and propagates in specimens subjected to compression loading. Also, microstructure and microhardness of the specimen were analyzed after experimental compression tests. FEA revealed that the occurrence and propagation of strains and deformations that led to the failure of specimens through the appearance of the shear band is in the same area as the specimens subjected to experimental compression tests.

The microstructure analysis revealed that under the action of compressive forces, oblique cracks appeared in the walls of the cells, which then contributed to the shear failure of the specimens. The authors believe that the microcracks which occurred in the material under the action of the compressive loading caused the decrease in the specimens' microhardness.

Acknowledgements: We hereby acknowledge to Transilvania University Schoolarship for International Mobilities 2016 program for financial suport, the Design School at Loughborough University, and structural funds project PRO-DD (POS-CCE, 0.2.2.1., ID 123, SMIS 2637, ctr. No 11/2009) for providing the infrastructure used in this work.

\section{References}

1. GIBSON, L.J ., ASHBY, M.F., Cambridge University Press, 1997, p. 1532

2. ASHBY, M. F., Phil. Trans. R. Soc. A, 364, 2006, p. 15

3. ASHBY, M.F., EVANS, A.G., FLECK, N.A., GIBSON, L.J ., HUTCHINSON, J.W., WADLEY, H.N.G., Butterworth-Heinemann Press, 2000, p. 1-263 4. SALVO, L., MARTIN, G., SUARD, M., MARMOTTANT, A., DENDIEVEL, R., BLANDIN, J.J., C. R. Physique, 15, 2014, p. 662

5. HAMED, Z., ONUR, Y., PU, Z., KEVIN, L., MESUT, K., ALBERT, C.T., Addit Manuf, 12, 2016, p. 274

6.MAITI, A. et al., Sci. Rep., 6, 2016, p.1

7.PETIT, C., Etude Des Proprietes Mecaniques De Materiaux Cellulaires Par Tomographie Aux Rayons X Et Modelisation Par Elements Finis. Doctoral Thesis, INSA Lyon, 2015, p. 1-228

8. AJOKU, U., HOPKINSON, N., CAINE, M., Materials Science and Engineering, 428, 2006, p. 211

9. SHEN, H., OPPENHEIMER, S.M., DUNAND, D.C., BRINSON, L.C.., Mechanics of Materials 38, 2006, p. 933

10. KADKHODAPOUR, J., MONTAZERIAN, H., RAEISI, S., Materials Science and Engineering C, 43, 2014, p. 587

11. MICHAILIDIS, N., STERGIOUDI, F., OMAR, H., PAPADOPOULOS, D., TSIPAS, D.N., Colloids and Surfaces A: Physicochem. Eng. Aspects, 382, 2011, p. 124

12. MARK, H., SUPACHAI, V., SAMI, K., Procedia CIRP 50, 2016, p. 94 13. GAYNOR, A.T., MEISEL, N.A., WILLIAMS, C.B., GUEST, J. K., J ournal of Manufacturing Science and Engineering, 136, 2014, p.1

14. *** Object500 Connex. Materials, www.Stratasys.com, accesed 17.04.2017

$\overline{\text { Manuscript received: } 25.07 .2018}$ 